\title{
Antarctic sea ice increase consistent with intrinsic variability of the Amundsen Sea Low
}

\author{
John Turner ${ }^{1}$ · J. Scott Hosking ${ }^{1}$ Gareth J. Marshall ${ }^{1}$ - Tony Phillips ${ }^{1}$ • \\ Thomas J. Bracegirdle ${ }^{1}$
}

Received: 15 October 2014 / Accepted: 8 June 2015 / Published online: 25 June 2015

(C) The Author(s) 2015. This article is published with open access at Springerlink.com

\begin{abstract}
We investigate the relationship between atmospheric circulation variability and the recent trends in Antarctic sea ice extent (SIE) using Coupled Model Intercomparison Project Phase 5 (CMIP5) atmospheric data, ECMWF Interim reanalysis fields and passive microwave satellite data processed with the Bootstrap version 2 algorithm. Over 1979-2013 the annual mean total Antarctic SIE increased at a rate of $195 \times 10^{3} \mathrm{~km}^{2} \mathrm{dec}^{-1}\left(1.6 \% \mathrm{dec}^{-1}\right)$, $p<0.01$. The largest regional positive trend of annual mean SIE of $119 \times 10^{3} \mathrm{~km}^{2} \mathrm{dec}^{-1}\left(4.0 \% \mathrm{dec}^{-1}\right)$ has been in the Ross Sea sector. Off West Antarctica there is a high correlation between trends in SIE and trends in the nearsurface winds. The Ross Sea SIE seasonal trends are positive throughout the year, but largest in spring. The stronger meridional flow over the Ross Sea has been driven by a deepening of the Amundsen Sea Low (ASL). Pre-industrial control and historical simulations from CMIP5 indicate that the observed deepening of the ASL and stronger southerly flow over the Ross Sea are within the bounds of modeled intrinsic variability. The spring trend would need to continue for another 11 years for it to fall outside the 2 standard deviation range seen in $90 \%$ of the simulations.
\end{abstract}

Keywords Sea ice - Southern Ocean - Climate change · Ross Sea $\cdot$ Amundsen Sea Low

John Turner

jtu@bas.ac.uk

1 British Antarctic Survey, Natural Environment Research Council, High Cross, Madingley Road,

Cambridge CB3 OET, UK

\section{Introduction}

A major question in global change studies is why has Antarctic sea ice extent (SIE) increased over recent decades when sea ice over the Arctic has been decreasing rapidly? Greenhouse gas (GHG) concentrations are now higher than at any time in the last one million years, and with the sensitivity of sea ice to increases in air and ocean temperature, it would be assumed intuitively that SIE in both polar regions would be declining. However, while Arctic sea ice reached a new record minimum extent in September 2012 (Parkinson and Comiso 2013), during the same month sea ice over the Southern Ocean attained a new maximum extent (Turner et al. 2013a), suggesting that the differences in SIE between the two polar regions are getting larger.

A further problem is that the majority of coupled climate models when run over recent decades with observed forcings have Antarctic sea ice decreasing in a manner similar to Arctic Sea ice (Eisenman et al. 2011). This may indicate that some process is not included in the current generation of climate models or that the observed trend over the admittedly short period since 1979 is at the extreme limit of the simulations produced by the climate models.

The record of reliable passive microwave satellite estimates of SIE begins in late 1978 with the availability of data from the Special Sensor Microwave Imager. During the first decade of the satellite record there was a slight decrease in Antarctic SIE, but subsequently a number of studies noted the statistically significant increase in extent (Cavalieri et al. 1997; Comiso and Nishio 2008; Zwally et al. 2002). However, it was often pointed out that this overall increase in SIE masked large regional variations and in particular a decrease in the Bellingshausen Sea (Parkinson and Cavalieri 2012; Stammerjohn et al. 2012) and 


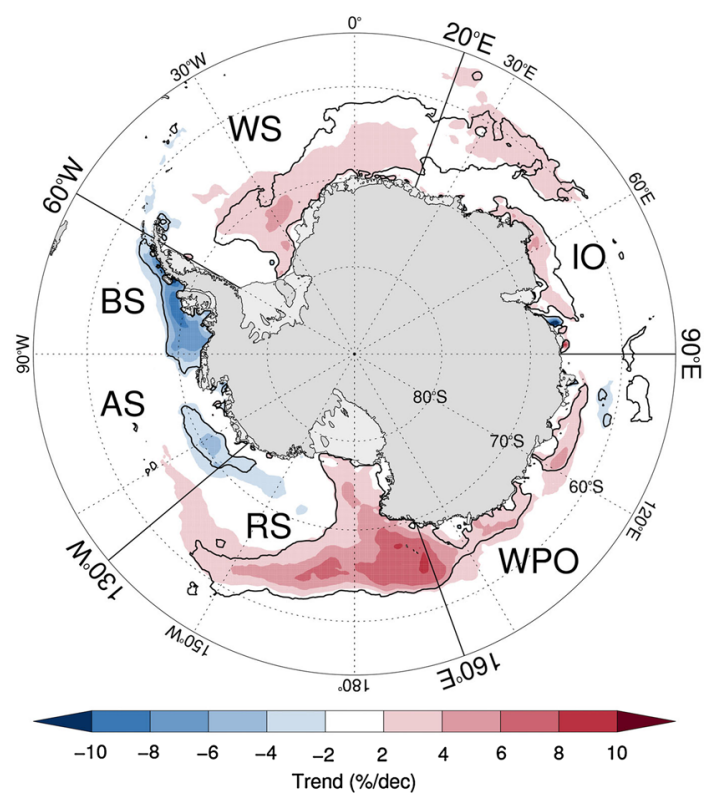

Fig. 1 The trend in annual mean sea ice concentration for 1979$2013\left(\% \mathrm{dec}^{-1}\right)$. Areas where the trend is significant at $p<0.05$ are enclosed by a bold line. Sectors discussed in this study are indicated-Weddell Sea (WS), Indian Ocean (IO), Western Pacific Ocean (WPO), Ross Sea (RS), Amundsen Sea (AS) and Bellingshausen Sea (BS)

increase in the Ross Sea (Comiso et al. 2011) (for places referred to in the text see Fig. 1).

A number of theories have been put forward to explain why the SIE is increasing. The West Antarctic Ice Sheet has been losing mass over recent decades, particularly from the Amundsen Sea Embayment area (Wingham et al. 2009), resulting in a freshening of the waters off the coast (Jacobs et al. 2002). Bintanja et al. (2013) suggested that the fresher water will impede the upward flux of heat from deeper levels and so contribute to the greater extent of ice in the Ross Sea. However, Swart and Fyfe (2013) carried out model experiments that injected freshwater into the Amundsen Sea and found that the resultant impact of such changes on the sea ice was small compared to internal variability. The role of such ice-ocean feedback processes was also examined by Zhang (2007), however, the process suggested involved an increase in near-surface air temperature, and this has not been observed at coastal stations beyond the Antarctic Peninsula (Turner et al. 2005).

The advection of sea ice is strongly influenced by the near-surface wind field and therefore the broadscale atmospheric circulation. Holland and Kwok (2012) used a dataset of satellite-tracked sea ice motion and atmospheric fields to investigate the relationship between the atmospheric circulation and sea ice anomalies. They found that wind-driven changes in ice advection were the dominant driver of ice trends around much of West
Antarctica, with wind-driven thermodynamic changes dominant elsewhere.

The contrasting SIE trends of increasing (decreasing) sea ice in the Ross (Bellingshausen) Sea and the known association between ice anomalies and the wind field suggests a link with the Amundsen Sea Low (ASL), which is the dominant climatological feature in this area (Fogt et al. 2012; Hosking et al. 2013; Turner et al. 2012a). Model results presented by Turner et al. (2009) suggested that the loss of stratospheric ozone had deepened the ASL, increasing the strength of the southerly winds over the Ross Sea and contributing to the increase of SIE in this area. However, not all models have ozone loss giving this deepening of the ASL.

The ASL is the deepest climatological mean sea level pressure (MSLP) centre within the circumpolar trough that rings Antarctica between $60^{\circ}$ and $70^{\circ} \mathrm{S}$, and its presence has been linked to the interaction between the orography of the Antarctic continent and the strength of the westerly winds over the Southern Ocean (Baines and Fraedrich 1989). Inter-annual variability of MSLP in the area of the ASL is larger than at any other location in the Southern Hemisphere (SH) (Connolley 1997; Lachlan-Cope et al. 2001), with surface pressure here influenced by tropical climate variability in the Pacific (Hoskins and Karoly 1981; Yuan and Martinson 2000) and Atlantic (Li et al. 2014; Simpkins et al. 2013) Oceans. The ASL has deepened in recent decades (Turner et al. 2009), which is consistent with the dipole of ice loss/increase between the Antarctic Peninsula and the Ross Sea.

In this paper we investigate the relationship between the trends in Antarctic SIE and the atmospheric circulation, and show that the increase of SH SIE since 1979, dominated by changes in the Ross Sea sector, is coincident with an increase in southerly near-surface winds associated with a deepening of the ASL. We examine trends in the depth of the ASL and winds over the Ross Sea in pre-industrial control, and historical runs covering the period since 1850, from the Coupled Model Intercomparison Project Phase 5 (CMIP5) of the World Climate Research Programme to investigate the intrinsic and forced variability of the atmospheric circulation off West Antarctica. Here we take intrinsic variability to mean the unforced, internal variability of the climate system. We choose to examine the near-surface wind field over the Ross Sea, which is the primary driver of SIE variability, rather than the SIE from the models directly since many of the models have difficulties in simulating the annual cycle and have long-term trends of SIE in their control runs (Turner et al. 2013b). The model control runs have fixed pre-industrial concentrations of GHGs, stratospheric ozone and aerosol, along with fixed solar forcing, and thus they allow us to estimate the intrinsic variability of the ASL and the winds over the Ross Sea. We also examine the ASL 
depth and Ross Sea wind trends in the CMIP5 historical runs in order to estimate the impact of GHG forcing on the atmospheric circulation in this area compared to intrinsic variability.

\section{Data and method}

Fields of monthly mean sea ice concentration (SIC) computed using the Bootstrap version 2 algorithm (Comiso 2000) were obtained on a $25 \mathrm{~km}$ resolution grid from the US National Snow and Ice Data Center (www.nsidc.org). A number of algorithms are available to convert the satellite passive microwave measurements to sea ice parameters, however, the differences between the resultant data are small (Ivanova et al. 2014). We decided to use the Bootstrap 2 data since it has been used in many previous studies and the sea ice trends in the recent IPCC Assessment Report 5 were determined using this algorithm. There is very close agreement between the sea ice trends determined using the Bootstrap 2 and NASA Team algorithms (Intergovernmental Panel on Climate Change 2013). Annual and seasonal mean SIEs were computed for the Antarctic as a whole and the five sectors (Weddell Sea, Indian Ocean, western Pacific Ocean, Ross Sea and Bellingshausen/Amundsen Sea) used in a number of earlier studies (e.g. Zwally et al. 2002) and shown on Fig. 1. SIE was computed as the total area of all $25 \mathrm{~km}$ boxes where the SIC exceeded $15 \%$. As in many previous studies, we examine linear trends in SIE since this is a good fit to the data.

Atmospheric circulation variability since 1979 was investigated using the ECMWF Interim reanalysis (ERA-Interim) fields, which have a grid spacing of $\sim 70 \mathrm{~km}$. Several studies have carried out intercomparisons of the various reanalysis data sets and concluded that the ERA-Interim data are of high quality. In particular, Bracegirdle (2013) assessed the Southern Ocean data in six reanalyses and concluded that ERA-Interim had the most accurate MSLP/surface winds between the Antarctic Peninsula and the Ross Sea. Monthly mean atmospheric fields from 51 CMIP5 control runs were obtained from the Program for Climate Model Diagnostics and Intercomparison (PCMDI) (http://cmip-pcmdi.llnl.gov/ cmip5/), with a total of $\sim 20,000$ years of control runs being available. For the computation of the correlations the time series of sea ice data and atmospheric fields were all detrended.

The trends were computed using a standard least-squares method, with the methodology used to calculate the significance levels based upon Santer et al. (2000). Briefly, an effective sample size was calculated based on the lag-1 autocorrelation coefficient of the regression residuals. This effective sample size was used for the computation of the
Table 1 Annual and seasonal trends in SH SIE $\left(10^{3} \mathrm{~km}^{2} \mathrm{dec}^{-1}\right)$ for 1979-2013 for the Antarctic as a whole and the five sectors shown on Fig. 1

\begin{tabular}{llllll}
\hline & Years & DJF & MAM & JJA & SON \\
\hline Whole Antarctic & $195^{* *}$ & $146^{*}$ & $226^{* *}$ & $180^{* *}$ & $206^{* *}$ \\
Ross Sea & $119^{*}$ & 98 & $107^{*}$ & $125^{* *}$ & $145^{*}$ \\
$\begin{array}{l}\text { Amundsen-Belling- } \\
\quad\end{array}$ & -51 & $-110^{* *}$ & $-114^{* *}$ & 1 & 5 \\
$\quad$ Whausen Seas & & & & & \\
Indian Ocean & 58 & 102 & $141^{*}$ & -36 & -22 \\
Western Pacific Ocean & 23 & 14 & 44 & 18 & 10 \\
\hline
\end{tabular}

Significance of the trends is indicated as follows $* * p<0.01$, $* p<0.05$

standard error and in indexing the critical values of Student's $t$ distribution.

\section{Results}

Over 1979-2013 the annual mean SH SIE has increased at a rate of $195 \times 10^{3} \mathrm{~km}^{2} \mathrm{dec}^{-1}\left(1.6 \% \mathrm{dec}^{-1}\right)$, which is significant at $p<0.01$ (Table 1). For the year as a whole SIE has increased by a small amount around the coast of East Antarctica and over the eastern Weddell Sea (Fig. 1). However, the largest increase has been in the Ross Sea sector (Comiso et al. 2011; Fan et al. 2014; Zwally et al. 2002) $\left(160^{\circ} \mathrm{E}-130^{\circ} \mathrm{W}\right)$, where the annual mean SIE has increased at a rate of $119 \times 10^{3} \mathrm{~km}^{2} \mathrm{dec}^{-1}(p<0.05)$ $\left(4.0 \% \mathrm{dec}^{-1}\right)$. SIE has increased in the Ross Sea sector throughout the year, with the smallest absolute trend (although the largest percentage trend of $5.8 \% \mathrm{dec}^{-1}$ ) in summer $\left(98 \times 10^{3} \mathrm{~km}^{2} \mathrm{dec}^{-1}\right)$, not significant as a result of the large inter-annual variability. The largest increase has been in spring $\left(145 \times 10^{3} \mathrm{~km}^{2} \mathrm{dec}^{-1}\right)\left(3.6 \% \mathrm{dec}^{-1}\right)$, with a trend significant at $p<0.05$. In this sector of the Southern Ocean the SIC anomalies show a high degree of spatial consistency between the seasons, with the positive anomalies being carried northwards at the ice edge through the growth phase (Fig. 2). At the time of sea ice minimum in late summer/early autumn the positive SIC anomalies in the Ross Sea sector are just to the west of $180^{\circ}$ off the coast of East Antarctica. However, through the winter and spring the positive SIC anomalies spread eastwards across $180^{\circ}$ as the sea ice edge advances sufficiently northwards to enter the climatological westerly wind belt and starts to be advected eastwards. By the time of the SIE maximum in late winter/early spring the positive SIC anomalies extend eastwards from $110^{\circ} \mathrm{E}$ to $110^{\circ} \mathrm{W}$, although the largest anomalies remain over the northern Ross Sea.

The annual mean SIE in the Ross Sea sector is significantly anti-correlated $(p<0.05)$ with the annual mean 
Fig. 2 The trend in SIC for the four seasons over 1979-2013 $\left(\% \mathrm{dec}^{-1}\right)$. Areas where the trend is significant at $p<0.05$ are enclosed by a bold line. $\mathbf{a}$ MAM, b JJA, c SON, d DJF
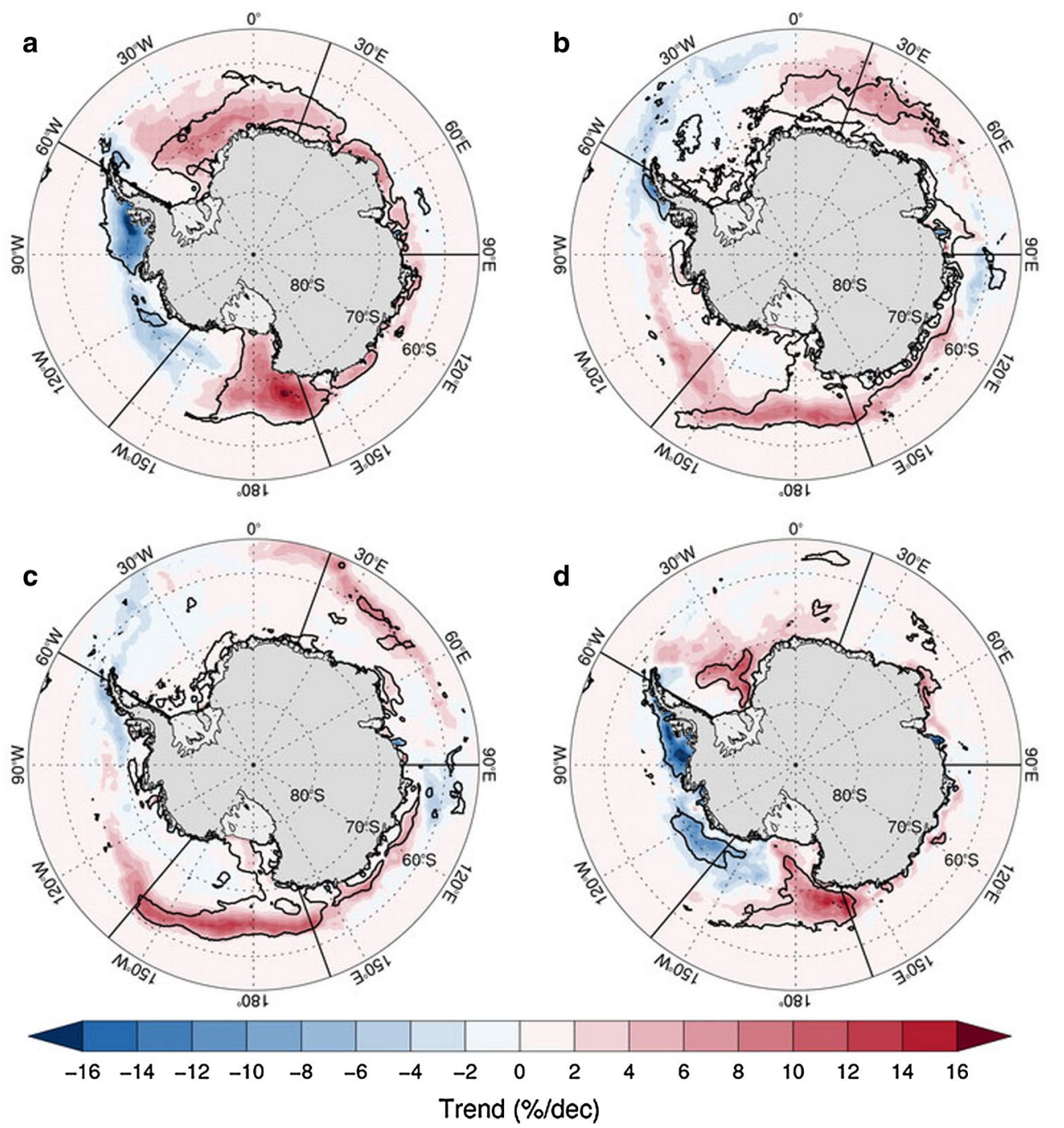

MSLP between the Antarctic Peninsula and the Ross Sea (Fig. 3a), which is the sector dominated by the ASL. A deeper (weaker) ASL is therefore associated with more (less) sea ice in the Ross Sea sector. In addition, the SIE is also positively correlated with MSLP to the north and northeast of the Ross Sea-a MSLP pattern that is associated with stronger winds over the southern South Pacific. The correlation of the annual mean SIE in the Ross Sea sector with the $200 \mathrm{hPa}$ zonal wind (Fig. 3b) shows a $p<0.05$ significant correlation (anticorrelation) with the upper tropospheric winds over the South Pacific in the latitude bands $45^{\circ}-60^{\circ} \mathrm{S}\left(30^{\circ}-45^{\circ} \mathrm{S}\right)$. A major feature of the upper tropospheric circulation of the southern Pacific Ocean is the split nature of the jet over the western Pacific Ocean (BalsElsholz et al. 2001). Here the circumpolar jet splits into the sub-tropical jet (STJ) and polar-front jet (PFJ), located to the north and south of New Zealand respectively. Figure $3 b$ shows that more (less) SIE in the Ross Sea sector is associated with a stronger PFJ (STJ). Such a 'flip-flop' in the strength of the two jets is seen between the two phases of ENSO (Chen et al. 1996), indicating the role played by tropical Pacific climate variability in modulating the atmospheric circulation in this sector of the Antarctic. A stronger jet south of New Zealand results in a deeper ASL since the Amundsen Sea is located in the right exit area of the jet, which favours upper level divergence and greater cyclogenesis in this region.

As the sea ice off West Antarctica is strongly influenced by the near-surface wind field (Holland and Kwok 2012), it is not surprising that the annual mean SIE in the Ross Sea sector is significantly correlated with the meridional component of the $10 \mathrm{~m}$ wind $\left(\mathrm{V}_{10}\right)$ across the Ross Sea (Fig. 3c) and especially the winds between $130^{\circ}-180^{\circ} \mathrm{W}$. However, the strong association between the SIE in the Ross Sea and the cyclonic circulation of the ASL means that the Ross Sea SIE is also anti-correlated with $\mathrm{V}_{10}$ over the Bellingshausen Sea; e.g. greater Ross SIE is associated with enhanced northerly flow west of the Antarctic Peninsula. Figure 3c also confirms that the annual mean SIE in the Ross Sea is influenced by the broadscale atmospheric circulation 
Fig. 3 a The correlation of the annual mean SIE in the Ross Sea with annual mean MSLP for 1979-2013. b The correlation of the annual mean SIE in the Ross Sea with the annual mean $200 \mathrm{hPa}$ zonal component of the wind for 1979-2013. c The correlation of the annual mean SIE in the Ross Sea with the annual mean $10 \mathrm{~m}$ meridional component of the wind for 1979-2013. d The trend in the annual mean MSLP for 1979-2013 (hPa year $\left.{ }^{-1}\right)$. Areas where the correlation or trend is significant at $p<0.05$ are enclosed by a bold line
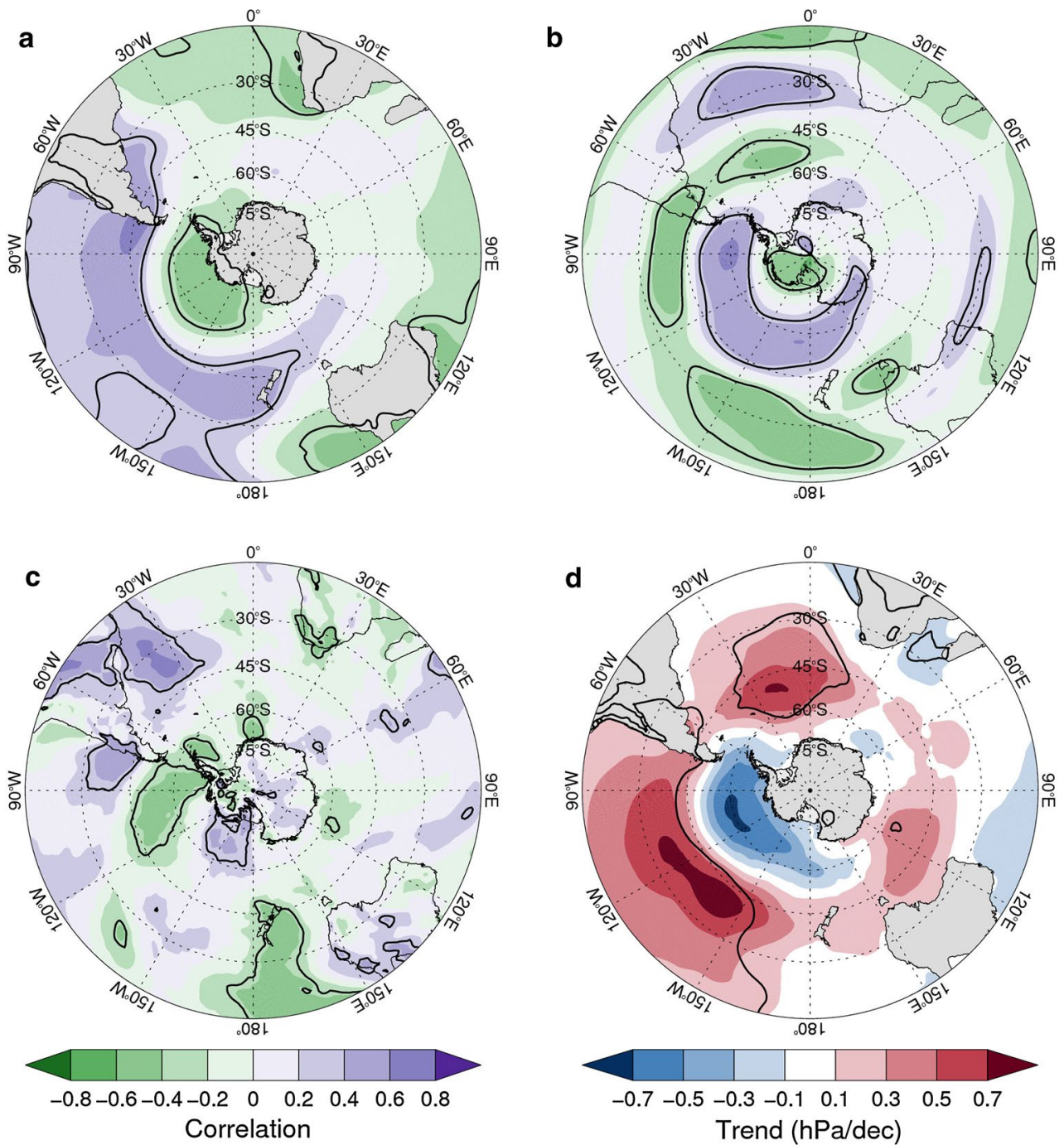

at mid- and high-latitude areas of the $\mathrm{SH}$ and beyond, but especially eastwards from Australia to the South Atlantic. Such a pattern of correlation indicates the linkages between Ross Sea SIE and the planetary waves around the Antarctic continent.

The ASL exhibits a marked annual cycle in its zonal location, being just to the west of the Antarctic Peninsula in summer and moving westward to the Ross Sea by winter (Hosking et al. 2013; Turner et al. 2012a). In contrast, its depth has a semi-annual form as a result of the SemiAnnual Oscillation, which gives the lowest MSLP values in spring and autumn (Turner et al. 2012a). The pattern of correlation between the Ross Sea SIE and MSLP varies over the year (Fig. 4). During the summer the Ross SIE is anti-correlated (correlated) with MSLP over the Antarctic continent (across $50-60^{\circ} \mathrm{S}$ ), indicating the importance of the Southern Annular Mode (SAM) at this time of year in influencing SIE (Simpkins et al. 2012). Although the pattern of anti-correlation between Ross SIE and MSLP is very zonally symmetric around the continent the largest anticorrelation in summer is in the Amundsen Sea. In the other three seasons there is a clear and significant $(p<0.05)$ maximum in anticorrelation between Ross SIE and MSLP over the Amundsen Sea, with the largest area of significant correlation being in the spring.

Although the depth of the ASL is broadly related to the SIE in the Ross Sea, it is the meridional component of the near-surface wind over the Ross Sea that has the most direct influence on SIE through the advection of ice northor south-wards. The seasonal correlation fields of Ross Sea SIE and $V_{10}$ vary markedly over the year (Fig. 5). In autumn the SIE is only significantly correlated with $\mathrm{V}_{10}$ over the Ross Ice Shelf and the southern part of the Ross Sea, indicating that it is the strength of the katabatic winds flowing down onto the ice shelf and extending out over the Ross Sea that is important in giving a positive SIE anomaly over the ocean. In the winter the Ross Sea SIE is significantly correlated with $\mathrm{V}_{10}$ over parts of the eastern Ross 
Fig. 4 The correlations of the seasonal mean SIE in the Ross Sea with MSLP for 1979-2013. a MAM, b JJA, c SON, d DJF
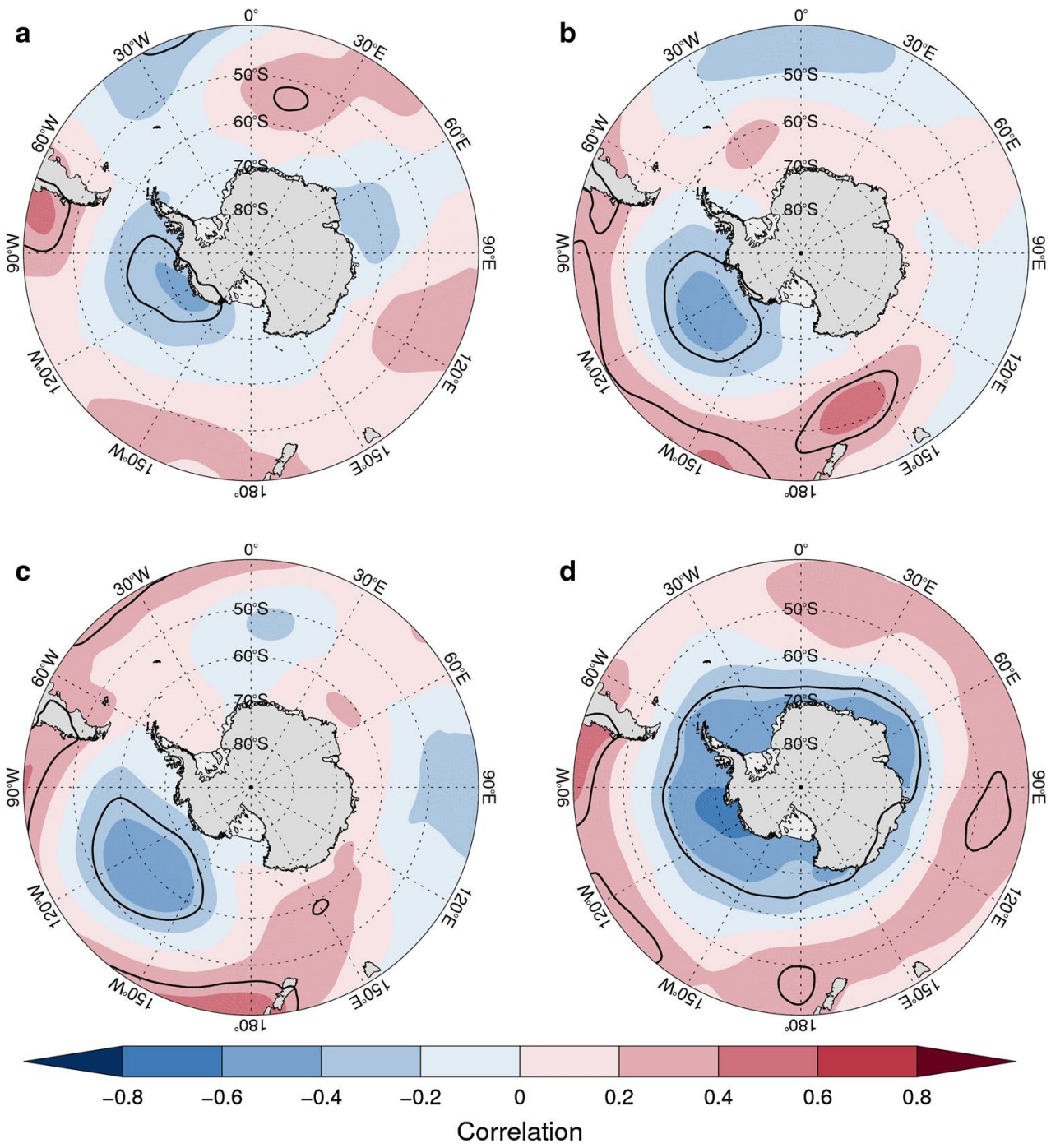

Ice Shelf, but also large parts of Victoria Land, indicating that the ice extent is influenced by the katabatic winds in the coastal area at a time when they are strongest. However, the SIE is also significantly correlated with $\mathrm{V}_{10}$ over much of the Ross Sea, indicating the importance of the synoptic conditions over the ocean as the ice begins to extend further north. In spring the Ross SIE is correlated with $\mathrm{V}_{10}$ over a large part of the Ross and Amundsen Seas, with correlation values of $>0.6$, but there is no significant correlation over the Antarctic continent or the coastal regions, indicating that synoptic conditions over the northern part of the sea ice zone have the greatest influence on the SIE. During summer the Ross SIE is only significantly correlated with $\mathrm{V}_{10}$ over a small area of the coastal region of the Amundsen Sea.

For the year as a whole the MSLP between the Antarctic Peninsula and the Ross Sea has decreased by up to $\sim-0.70 \mathrm{hPa} \mathrm{dec}{ }^{-1}$ (Fig. 3d), although the trend is not significant. However, this has strengthened the climatological southerly winds over the Ross Sea by up to $\sim 0.15 \mathrm{~m} \mathrm{~s}^{-1} \mathrm{dec}^{-1}$ ( $p<0.05$ ) (up to $\sim 8 \%$ over the 35 years). The trend in the depth of the ASL varies markedly over the year, with consequent impact on the changes in $\mathrm{V}_{10}$ over the Ross Sea and SIE in the Ross Sea. The deepening of the ASL of $\sim 1.8 \mathrm{hPa} \mathrm{dec}{ }^{-1}$ has been largest in the autumn, although the largest decrease in MSLP was over the Bellingshausen Sea, so that the impact on the sea ice of the Ross Sea was limited. However, in spring the MSLP over the northern Ross Sea has decreased by up to $\sim 1.2 \mathrm{hPa} \mathrm{dec}{ }^{-1}$, which is an optimal location to increase the strength of the southerly wind near the sea ice edge.

The changes in atmospheric circulation off West Antarctica in recent decades could be the result of alterations in one or more of the forcing factors that affect the area, such as changes in tropical SSTs or the loss of stratospheric ozone, or could be the result of intrinsic variability within the climate system. Estimating the impact on individual forcing factors is difficult, but it is instructive to examine 
Fig. 5 The correlations of the seasonal mean SIE in the Ross Sea with $\mathrm{V}_{10}$ for 1979-2013. a MAM, b JJA, c SON, d DJF
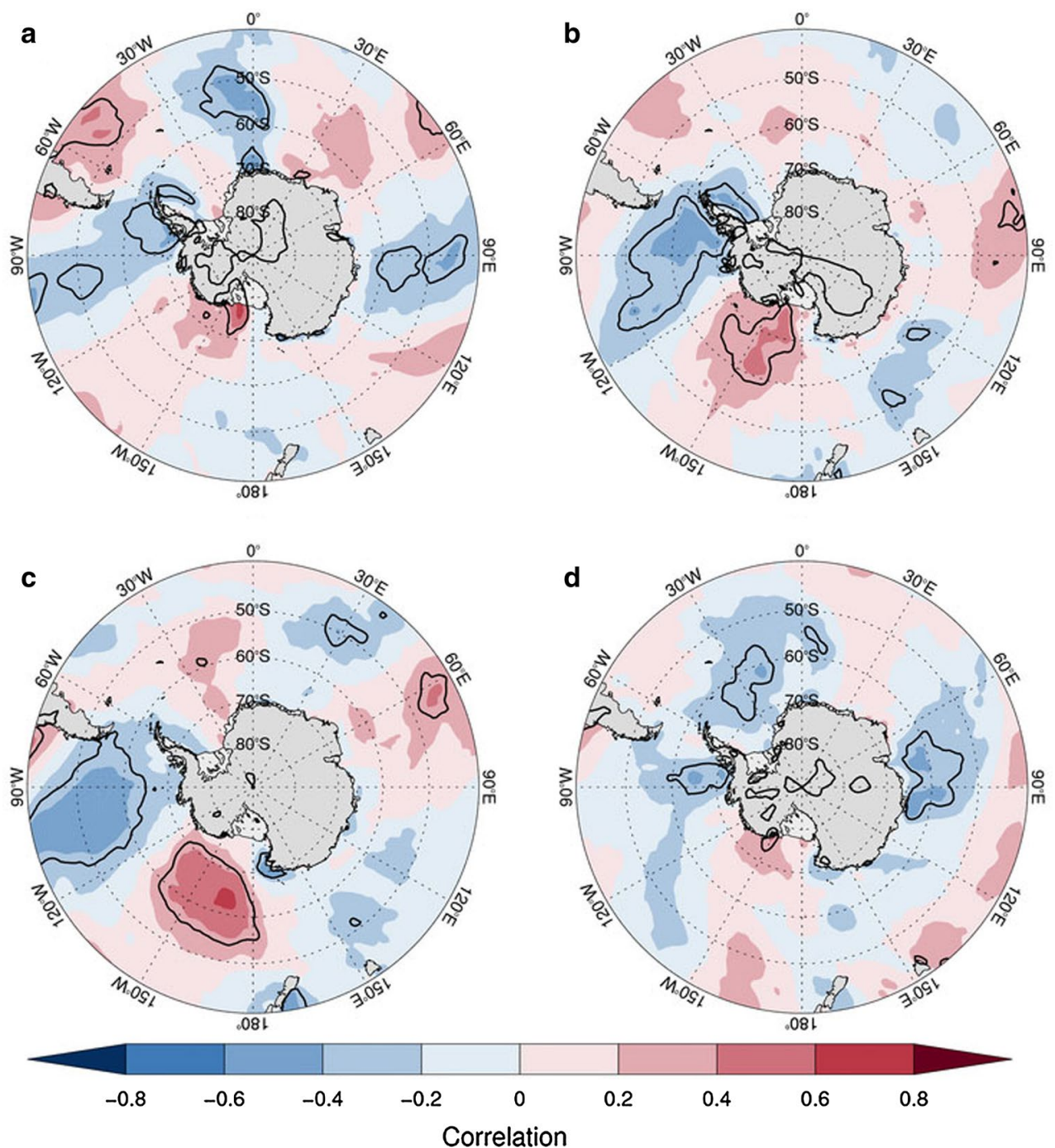

the magnitude of the intrinsic variability of the key atmospheric drivers of sea ice variability in this area to determine if the recent observed changes are exceptional.

In order to investigate whether the changes in the atmospheric circulation off West Antarctica are within the bounds of intrinsic variability we have divided the $\sim 20,000$ years of output from the 51 CMIP5 model control runs into 35 year periods with a 1 year separation. The 35 year trend was selected since it corresponds to the length of the period for which we have reliable reanalysis data. We examined two quantities in the control runs. Firstly, the 35 year trends in the depth of the ASL, which we determined from the mean MSLP over $60^{\circ}-75^{\circ} \mathrm{S}, 170^{\circ} \mathrm{E}-75^{\circ} \mathrm{W}$. Secondly, the 35 year trends in $\mathrm{V}_{10}$ over the Ross Sea sector of $60^{\circ}-75^{\circ} \mathrm{S}$, $160^{\circ} \mathrm{E}-130^{\circ} \mathrm{W}$.

Figure 6 illustrates the annual trends in the ASL depth and mean $\mathrm{V}_{10}$ over the Ross Sea sector in the CMIP5 model control runs using box and whisker plots. They show the trends since 1979 determined from the ERA-Interim data (indicated by red lines) and the distribution of all 35 year trends for each model run and across all model runs.

For the MSLP in the region of the ASL, the annual trend observed since 1979 is outside the inter-quartile range for all the models and also the multi-model mean. However, it is within the two standard deviation (SD) range of all the models. The drop in MSLP observed since 1979 is therefore not exceptional compared to the model control runs, even though these 35 years are unique in that it is the period over which there has been a loss of stratospheric ozone. The development of the 'ozone hole' has resulted in a higher frequency of the SAM being in its positive phase in austral summer and autumn (e.g. Thompson et al. 2011) and has been associated with a decrease of MSLP around Antarctica.

The strength of the meridional component of the nearsurface wind over the Ross Sea is significantly correlated with the SIE in this sector of the Southern Ocean. Figure $6 \mathrm{~b}$ shows that the observed trend in $\mathrm{V}_{10}$ since 1979 
Fig. 6 The distribution of 35 -year annual trends in the CMIP5 pre-industrial control runs and the observed trends for 1979-2013. a Annual mean MSLP for $60^{\circ}-75^{\circ} \mathrm{S}$, $75^{\circ} \mathrm{W}-170^{\circ} \mathrm{E} . \mathbf{b ~ V}_{10}$ for $60^{\circ}-75^{\circ} \mathrm{S}, 130^{\circ} \mathrm{W}-160^{\circ} \mathrm{E}$. The open circles show the mean and \pm 2 standard deviation range of the distribution of model trends. The values on the right show where the observed trend (the red line) falls in the model's trend distribution (in standard deviations from the mean). The numbers introduced by $\mathrm{n}=$ on the left show the number of 35 year trends in each distribution. The distribution of trends across all the control and historical runs is shown at the bottom 35-year trends in ASL region annual mean MSLP by CMIP5 control run and ERA-Interim annual mean MSLP trend for 1979-2013

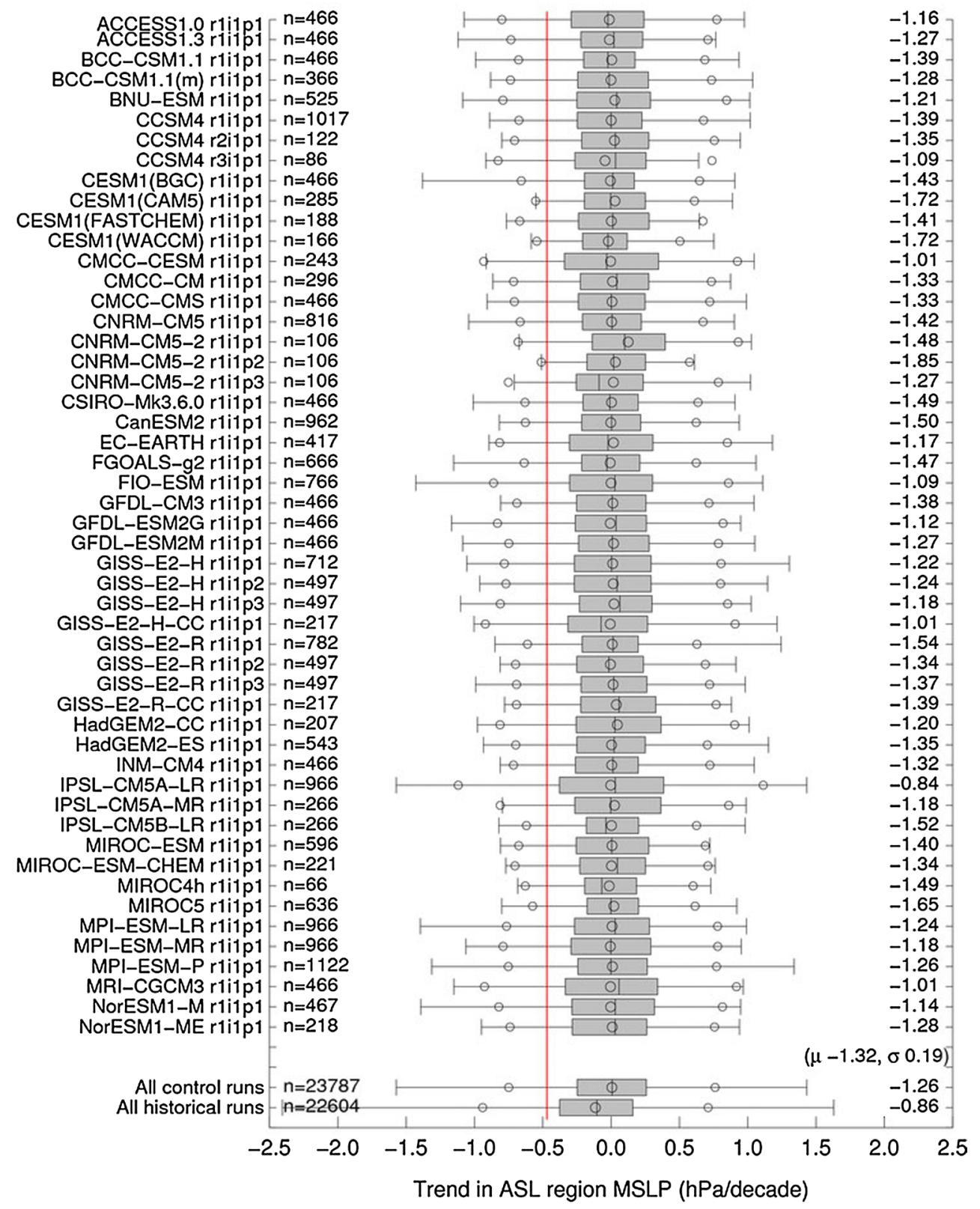

near-surface winds, and that the changes are dominated by internal variability.

Considering the seasonal data (not shown), in winter the observed trends in ASL MSLP and Ross $\mathrm{V}_{10}$ are both very small and close to the model mean trends, and are within the 2 SD range of every CMIP5 model. The observed summer deepening of the ASL can be attributed largely to the loss of stratospheric ozone, which is not present in the pre-industrial control runs. The observed trend is therefore beyond the $2 \mathrm{SD}$ range of trends in three of the models. In contrast, the observed trend in Ross Sea $\mathrm{V}_{10}$ is smaller and 
Fig. 6 continued 35-year trends in Ross Sea annual mean V10 by CMIP5 control run and ERA-Interim annual mean v10 trend for 1979-2013

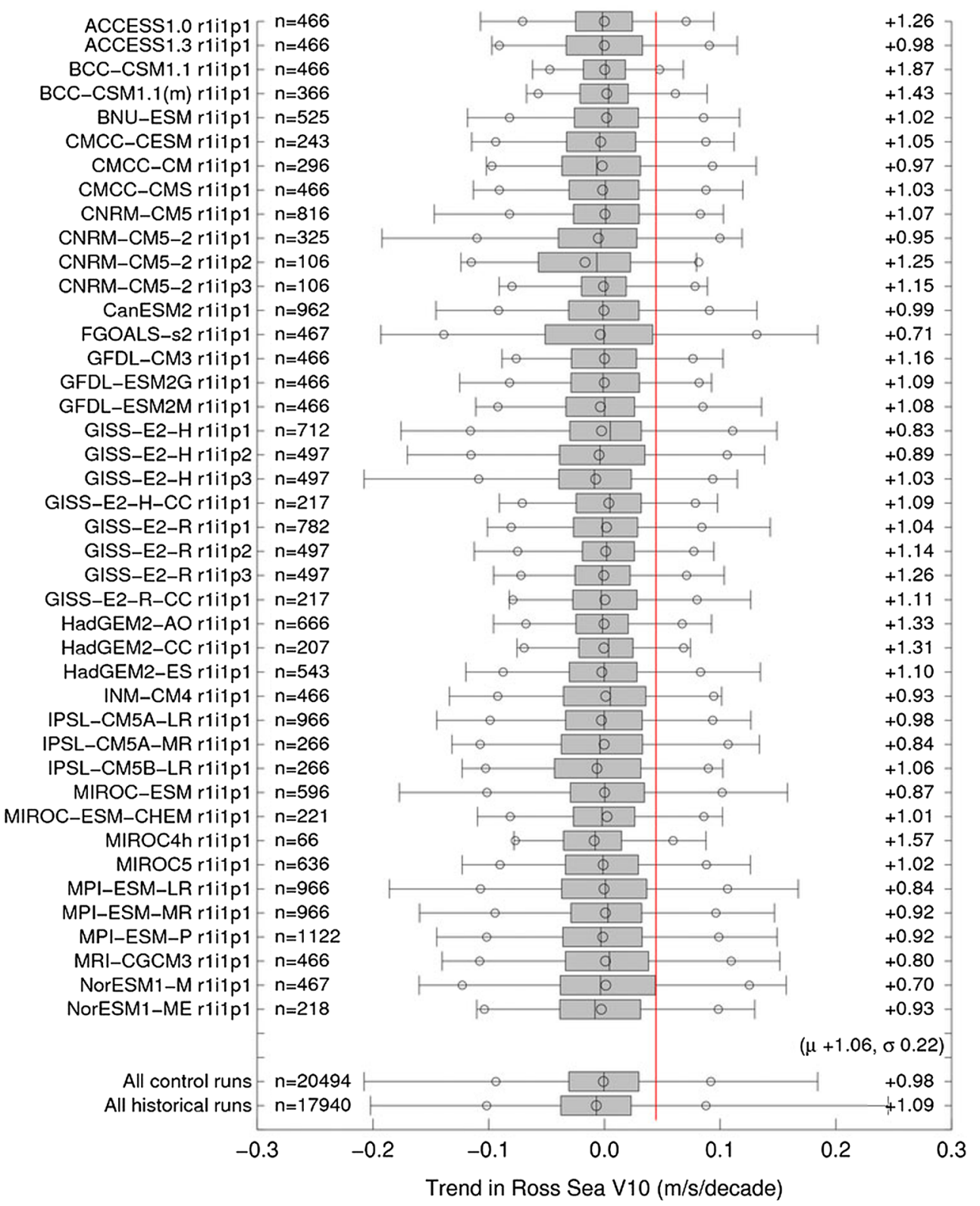

within the 2 SD range of all the models. The multi-model mean ASL depth in the historical runs has decreased since the 1970s at a rate similar to that observed, as the SAM has become more positive and summer MSLP decreased all around the Antarctic. However, the historical runs do not show any marked differences in Ross Sea $\mathrm{V}_{10}$ trends compared to the control runs.

The seasons of largest observed increase in Ross Sea $\mathrm{V}_{10}$ are autumn and spring. In the autumn the marked decrease of MSLP of $0.08 \mathrm{hPa} \mathrm{dec}^{-1}$ is beyond the $2 \mathrm{SD}$ range of 14 of the models, however, the observed deepening has been close to the Antarctic Peninsula so that the observed increase of Ross $\mathrm{V}_{10}$ is relatively modest and within the 2 SD range of all 51 CMIP5 models. The Ross Sea $\mathrm{V}_{10}$ has increased most during spring, with the trend of $0.14 \mathrm{~m} \mathrm{~s}^{-1} \mathrm{dec}^{-1}$ being a major factor in giving the largest seasonal trend in Ross Sea SIE. The observed trend in ASL depth was not particularly large, but the decrease in MSLP was over the northern Amundsen and Ross Seas, so that the stronger southerly flow advected the sea ice northwards in the Ross Sea. The observed increase in Ross $\mathrm{V}_{10}$ was beyond the $2 \mathrm{SD}$ range of four CMIP5 models, although within the multi-model mean 2 SD range. 


\section{Discussion}

The intrinsic variability of the ASL, which in turn drives the strength of the southerly $\mathrm{V}_{10}$ over the Ross Sea, has a number of contributing factors, including tropical forcing (Simpkins et al. 2012), the phase of the SAM, as well as regional flow-orography interactions. In addition, atmosphere-ocean feedback will also play a part (Goosse and Zunz 2014). Quantifying the contributions from these different forcing factors and relating them to the observed changes since 1979 presents a number of problems since tropical-high latitude teleconnections are poorly represented in many climate models and it is difficult to conduct experiments that isolate individual factors in a realistic manner. SSTs across various sectors of the tropical oceans have increased over recent decades, which will have deepened the ASL (Hoskins and Karoly 1981; Li et al. 2015). However, increases in SSTs in the southwestern tropical and subtropical Pacific have also been put forward as influencing the ASL, especially during the spring, with the teleconnections being established via the Pacific South American mode (Schneider et al. 2012).

Although we have a comparatively short record of reliable atmospheric analyses with which to investigate circulation variability, some station data and proxy records can give a broad indication of changes on longer time scales. The in situ meteorological records from Faraday/Vernadsky station on the western side of the Antarctic Peninsula show a warming at the location since the late 1940s, which has been linked to a decrease in sea ice off the coast and a deepening of the ASL (Turner et al. 2012b). However, a 308 year ice core record from Ellsworth Land suggests that such periods of warming are not unique, with larger isotopic warming (and cooling) trends having occurred in the mid-nineteenth and eighteenth centuries (Thomas et al. 2013). This was interpreted as indicating that at the moment anthropogenic forcing at this location had not exceeded the natural range of climate variability in the context of the past $\sim 300$ years. The control runs of the CMIP5 models examined here also suggest that the atmospheric circulation changes that have occurred since the late 1970s are within the bounds of intrinsic variability, and that with the strong correlation between SIE and the wind field, that the sea ice increase in the region is dominated by intrinsic variability of the ASL. This result is consistent with the assessment of sea ice variability in four of the CMIP5 models, which showed large intrinsic variability (Polvani and Smith 2013). In addition, the similar ranges in ASL depth and Ross Sea $V_{10}$ trends in the pre-industrial control and historical runs suggests that intrinsic/internal variability in these quantities is large compared to the effects of GHG increases.
Antarctic SIE reached record daily maxima during September in both 2012 and 2014, resulting in a great deal of discussion regarding possible reasons for the upward trend. While the above suggests that the trend since 1979 is still within the bounds of intrinsic variability, it is interesting to consider when a continued increase of $\mathrm{V}_{10}$ at the present rate would suggest this is not the case. We have therefore compared the trend of Ross Sea $\mathrm{V}_{10}$ as determined from ERA-Interim over the period 1979-2013 with the distributions of CMIP5 control run trends in the same area for periods of length 10-80 years (applying a similar methodology to that used to produce Fig. 6). This allows us to determine the proportion of simulations for which the observed trend is outside the $\pm 2 \mathrm{SD}$ range. The largest observed trend in $\mathrm{V}_{10}$ has been in spring and our analysis suggests that if the current trend continues for a further 7 (11) years then it will be outside the 2 SD range of more than $50 \%$ (90\%) of the CMIP5 model control runs. This indicates that if the current upward trend in Antarctic SIE continues at its present rate it will soon become harder to reconcile the observed increase with our understanding of intrinsic variability of the atmosphere-ocean-sea ice system of high southern latitudes.

The contrasting signs of the recent SIE trends in the two polar regions does initially seem surprising and has prompted a great deal of debate regarding the reasons behind these changes. Clearly the topography of the two polar regions is very different, as is the meridional locations of the sea ice zones in the Arctic and Antarctic. In addition, over the period of the satellite-derived sea ice record the Antarctic has experienced a marked loss of stratospheric ozone each spring, which has resulted in farreached atmospheric and oceanic changes across the $\mathrm{SH}$. So large differences in the climates of the Arctic and Antarctic are to be expected. However, the fact that the SH sea ice has increased over the last 35 years while $95 \%$ of the climate model 'historical' runs over this period have sea ice decreasing is unexpected. There may be some mechanism missing from the current generation of climate models that is critical in simulating the increase of Antarctic sea ice over recent decades. But this seems unlikely since the SIE trend is dominated by the increase of ice in the Ross Sea sector and the sea ice changes here as so closely linked to the observed changes in atmospheric circulation. The observed deepening of the ASL and strengthening of the meridional winds over the Ross Sea will be a result of a number of factors, but the overall trend seems to be within the bounds of intrinsic variability of the climate in this area, which is consistent with the large atmospheric circulation variability inferred from signals in ice cores providing data for the last few 100 years. With such large natural climate variability a positive trend in SIE over 35 years is 
not totally unexpected, although it is near the limit of the intrinsic variability as estimated from the climate models.

Acknowledgments This work was financially supported by the UK Natural Environment Research Council under Grant NE/H02333X/1. We are grateful to PCMDI for making the CMIP5 data available and to ECMWF for the provision of reanalysis fields.

Open Access This article is distributed under the terms of the Creative Commons Attribution 4.0 International License (http://creativecommons.org/licenses/by/4.0/), which permits unrestricted use, distribution, and reproduction in any medium, provided you give appropriate credit to the original author(s) and the source, provide a link to the Creative Commons license, and indicate if changes were made.

\section{References}

Baines PG, Fraedrich K (1989) Topographic effects on the mean tropospheric flow patterns around Antarctica. J Atmos Sci 46:3401-3415

Bals-Elsholz TM, Atallah EH, Bosart LF, Wasula TA, Cempa MJ, Lupo AR (2001) The wintertime Southern Hemisphere split jet: structure, variability, and evolution. J Clim 14:4191-4215

Bintanja R, van Oldenborgh Drijfhout SS, Wouters B, Katsman CA (2013) Important role for ocean warming and increased ice-shelf melt in Antarctic sea-ice expansion. Nat Geosci. doi:10.1038/ NGEO1767

Bracegirdle TJ (2013) Climatology and recent increase of westerly winds over the Amundsen Sea derived from six reanalyses. Int J Climatol 33(4):843-851

Cavalieri DJ, Gloersen P, Parkinson CL, Comiso JC, Zwally HJ (1997) Observed hemispheric asymmetry in global sea ice changes. Science 278(5340):1104-1106

Chen B, Smith SR, Bromwich DH (1996) Evolution of the tropospheric split jet over the south Pacific Ocean during the 1986-89 ENSO cycle. Mon Weather Rev 124(8):1711-1731

Comiso JC (2000) Bootstrap sea ice concentrations from Nimbus-7 SMMR and DMSP SSM/I-SSMIS. Version 2. Updated 2012. Boulder, Colorado, NASA DAAC at the National Snow and Ice Data Center

Comiso JC, Nishio F (2008) Trends in the sea ice cover using enhanced and compatible AMSR-E, SSM/I and SMMR data. J Geophys Res 113:C02S07. doi:10.1029/2007JC004257

Comiso JC, Kwok R, Martin S, Gordon AL (2011) Variability and trends in sea ice extent and ice production in the Ross Sea. J Geophys Res. doi:10.1029/2010JC006391

Connolley WM (1997) Variability in annual mean circulation in southern high latitudes. Clim Dyn 13:745-756

Eisenman I, Schneider T, Battisti DS, Bitz CM (2011) Consistent changes in the sea ice seasonal cycle in response to global warming. J Clim 24(20):5325-5335

Fan TT, Deser C, Schneider DP (2014) Recent Antarctic sea ice trends in the context of Southern Ocean surface climate variations since 1950. Geophys Res Lett 41(7):2419-2426

Fogt RL, Wovrosh AJ, Langen RA, Simmonds I (2012) The characteristic variability and connection to the underlying synoptic activity of the Amundsen-Bellingshausen Seas low. J Geophys Res. doi:10.1029/2011JD017337

Goosse H, Zunz V (2014) Decadal trends in the Antarctic sea ice extent ultimately controlled by ice-ocean feedback. Cryosphere $8(2): 453-470$
Holland PR, Kwok R (2012) Wind-driven trends in Antarctic sea-ice drift. Nat Geosci 5(12):872-875

Hosking JS, Orr A, Marshall GJ, Turner J, Phillips T (2013) The influence of the Amundsen-Bellingshausen Seas low on the climate of West Antarctica and its representation in coupled climate model simulations. J Clim 26:6633-6648

Hoskins BJ, Karoly DJ (1981) The steady linear response of a spherical atmosphere to thermal and orographic forcing. J Atmos Sci 38:1179-1196

Intergovernmental Panel on Climate Change (2013) Climate change 2013: the physical science basis. Cambridge University Press, Cambridge

Ivanova N, Johannessen OM, Pedersen LT, Tonboe RT (2014) Retrieval of Arctic sea ice parameters by satellite passive microwave sensors: a comparison of eleven sea ice concentration algorithms. IEEE Trans Geosci Remote Sens 52(11):7233-7246

Jacobs SS, Giulivi CF, Mele PA (2002) Freshening of the Ross Sea during the late 20th century. Science 297:386-389

Lachlan-Cope TA, Connolley WM, Turner J (2001) The role of the non-axisymmetric Antarctic orography in forcing the observed pattern of variability of the Antarctic climate. Geophys Res Lett 28(21):4111-4114

Li XC, Holland DM, Gerber EP, Yoo C (2014) Impacts of the north and tropical Atlantic Ocean on the Antarctic Peninsula and sea ice. Nature 505(7484):538-542. doi:10.1038/nature12945

Li X, Gerber EP, Holland DM, Yoo C (2015) A Rossby wave bridge from the tropical Atlantic to West Antartica. J Clim 28:2256-2273

Parkinson CL, Cavalieri DJ (2012) Antarctic sea ice variability and trends, 1979-2010. Cryosphere 6:871-880

Parkinson CL, Comiso JC (2013) On the 2012 record low Arctic sea ice cover: combined impact of preconditioning and an August storm. Geophys Res Lett 40(7):1356-1361. doi:10.1002/GRL.50349

Polvani LM, Smith KL (2013) Can natural variability explain observed Antarctic sea ice trends? New modelling evidence from CMIP5. Geophys Res Lett. doi:10.1002/grl.50578

Santer BD, Wigley TML, Boyle JS, Gaffen DJ, Hnilo JJ, Nychka D, Parker DE, Taylor KE (2000) Statistical significance of trends and trend differences in layer-average atmospheric temperature time series. J Geophys Res 105(D6):7337-7356

Schneider DP, Deser C, Okumura Y (2012) An assessment and interpretation of the observed warming of West Antarctica in the austral spring. Clim Dyn 38(1-2):323-347

Simpkins GR, Ciasto LM, Thompson DWJ, England MH (2012) Seasonal relationships between large-scale climate variability and Antarctic sea ice concentration. J Clim 25(16):5451-5469

Simpkins GR, Ciasto LM, England MH (2013) Observed variations in multidecadal Antarctic sea ice trends during 1979-2012. Geophys Res Lett 40(14):3643-3648

Stammerjohn S, Massom R, Rind D, Martinson D (2012) Regions of rapid sea ice change: an inter-hemispheric seasonal comparison. Geophys Res Lett. doi:10.1029/2012g1050874

Swart NC, Fyfe JC (2013) The influence of recent Antarctic ice sheet retreat on simulated sea ice area trends. Geophys Res Lett 40(16):4328-4332. doi:10.1002/grl.50820

Thomas ER, Bracegirdle TJ, Turner J, Wolff EW (2013) A 308 year record of climate variability in West Antarctica. Geophys Res Lett 40(20):5492-5496

Thompson DWJ, Solomon S, Kushner PJ, England MH, Grise KM, Karoly DJ (2011) Signatures of the Antarctic ozone hole in Southern Hemisphere surface climate change. Nat Geosci 4(11):741-749

Turner J, Colwell SR, Marshall GJ, Lachlan-Cope TA, Carleton AM, Jones PD, Lagun V, Reid PA, Iagovkina S (2005) Antarctic climate change during the last 50 years. Int J Climatol 25:279-294

Turner J, Comiso JC, Marshall GJ, Lachlan-Cope TA, Bracegirdle TJ, Maksym T, Meredith MP, Wang Z, Orr A (2009) Non-annular 
atmospheric circulation change induced by stratospheric ozone depletion and its role in the recent increase of Antarctic sea ice extent. Geophys Res Lett 36:L08502. doi:10.1029/200 9GL037524

Turner J, Phillips T, Hosking S, Marshall GJ, Orr A (2012a) The Amundsen Sea Low. Int J Climatol 33:1818-1829

Turner J, Maksym T, Phillips T, Marshall GJ, Meredith MP (2012b) Impact of changes in sea ice advance on the large winter warming on the western Antarctic Peninsula. Int J Climatol 33:852-861

Turner J, Bracegirdle TJ, Phillips T, Marshall GJ, Hosking JS (2013a) An initial assessment of Antarctic sea ice extent in the CMIP5 models. J Clim 26:1473-1484
Turner J, Hosking JS, Phillips T, Marshall GJ (2013b) Temporal and spatial evolution of the Antarctic sea ice prior to the September 2012 record maximum extent. Geophys Res Lett 40:5894-5898

Wingham DJ, Wallis DW, Shepherd A (2009) Spatial and temporal evolution of Pine Island Glacier thinning, 1995-2006. Geophys Res Lett. doi:10.1029/2009GL039126

Yuan X, Martinson DG (2000) Antarctic sea ice extent variability and its global connectivity. J Clim 13:1697-1717

Zhang J (2007) Increasing Antarctic sea ice under warming atmospheric and oceanic conditions. J Clim 20:2515-2529

Zwally HJ, Comiso JC, Parkinson CL, Cavalieri DJ, Gloersen P (2002) Variability of Antarctic sea ice 1979-1998. J Geophys Res. doi:10.1029/2000JC000733 